Original Research

\title{
Fenomena Phubbing: Suatu Degradasi Relasi Sosial Sebagai Dampak Media Sosial
}

\author{
Rafinitia Aditia ${ }^{1 *}$ \\ ${ }^{1}$ Fakultas Ilmu Sosial dan Politik, Universitas Bengkulu, Bengkulu-Indonesia \\ * corresponding author: rafinitiaaditiaa@gmail.com
}

\begin{abstract}
This study aims to find out about the phubbing phenomenon as a degradation of social relations as a result of social media. The term phubbing is an abbreviation of the words phone and snubbing, which are used to show the attitude of hurting the other person by using an excessive smartphone. This type of research used a qualitative approach with descriptive methods. The data needed in this study are qualitative data as primary data in the form of images, words and not numbers in a discourse regarding the phubbing phenomenon as a degradation of social relations as a result of social media. Based on the results of the research, it is found that phubbing behavior can threaten the disruption of ongoing communication relationships, causing social degradation. The social degradation that occurs is due to the impact of phubbing perpetrators' indifference to their environment because they are too busy using smartphones, especially in the use of social media. Therefore it is necessary to limit and control the use of social media properly so that the phubbing phenomenon can be resolved immediately and the degradation of social relations does not occur.
\end{abstract}

Keywords: phubbing, degradation, social relation, social media

Abstrak-Penelitian ini bertujuan untuk mengetahui tentang tentang fenomena phubbing sebagai suatu degradasi relasi sosial sebagai dampak dari media sosial. Jenis penelitian yang digunakan menggunakan pendekatan kualitatif dengan metode deskriptif. Data yang dibutuhkan dalam penelitian ini merupakan data kualitatif sebagai data primer berupa gambar, kata-kata dan bukan angka-angka dalam sebuah wacana mengenai fenomena phubbing sebagai suatu degradasi relasi sosial sebagai dampak dari media sosial. Berdasarkan hasil penelitian diperoleh hasil bahwa perilaku phubbing mampu mengancam terganggunya hubungan komunikasi yang sedang berlangsung, sehingga menyebabkan degradasi sosial. Degradasi sosial yang terjadi ialah karena dampak dari keacuhan pelaku phubbing terhadap lingkungannya karena terlalu sibuk menggunakan smartphone, terlebih dalam penggunaan media sosial. Oleh karena itu penggunaan media sosial perlu dibatasi dan dikontrol dengan baik agar fenomena phubbing dapat segera teratasi dan degradasi relasi sosial tidak terjadi.

Kata kunci: phubbing, degradasi, hubungan sosial, sosial media

\section{PENDAHULUAN}

Fitrah manusia sebagai makhluk sosial menjadikan manusia tidak akan bisa terlepas dari proses komunikasi. Komunikasi ialah suatu hal yang pasti dimiliki oleh setiap individu (Fitria, R; Aditia, R: 2019). Salah satu bentuk dari komunikasi ialah dengan komunikasi langsung secara tatap muka yang membuat setiap individu mampu untuk saling mengenal, saling berbagi informasi, dan saling bertukar pikiran dan ide yang dimiliki. Selama beberapa dekade, komunikasi langsung dianggap sebagai komunikasi yang paling efektif untuk digunakan dalam segala situasi dan kondisi. Hal ini dikarenakan komunikasi langsung terjadi tanpa menggunakan media perantara sebagai penghantar pesan maupun informasi dari komunikator ke komunikan. Namun seiring dengan perkembangan teknologi yang terjadi, hadirnya media baru berupa internet dan smartphone membuat kegiatan komunikasi secara tatap muka semakin jarang dilakukan karena setiap individu lebih memilih asik bermain dengan gawai atau smartphone yang dimiliki dibanding harus berkomunikasi langsung dengan orang lain.

Kehadiran Smartphone ditengah era globalisasi yang menuntut setiap orang mampu menjadi lebih update terhadap dunia yang penuh teknologi malah menjadikan smartphone sebagai salah hal yang tidak lagi dapat dipisahkan dari kehidupan. Segala informasi mampu diperoleh dengan cepat melalui smartphone, mulai dari informasi resep kue sederhana atau bahkan informasi mengenai fenomena yang terjadi di setiap penjuru dunia. Begitupula dengan proses komunikasi, smartphone memungkinkan setiap individu untuk mampu berkomunikasi dengan siapa saja dan di mana saja, memfasilitasi interaksi sosial dengan orang-orang yang sangat dekat, atau di sisi lain dunia.

Ditengah banyaknya keuntungan nyata dalam menyatukan orang-orang, smartphone terkadang dapat membuat orang terpisah (Turkle, 2011). Sebagai salah satu media berbasis digital, smartphone tentu memiliki peluang yang besar di masyarakat. Dibuktikan dengan 
perkembangan dunia digital yang cukup pesat di Indonesia, dimana $91 \%$ penduduk Indonesia menggunakan telepon genggam dan $60 \%$ nya merupakan smartphone. Lebih lagi ketika smartphone bergabung dengan internet dan menghasilkan sebuah media sosial. Hal ini akan mengakibatkan beberapa fenomena perubahan sosial di masyarakat, seperti berubahnya pola perilaku individu dengan orang di sekitar ketika mereka asyik bermain media sosial di smartphone, atau bahkan hanya dengan getaran smartphone saja individu mampu langsung teralihkan dari komunikasi langsung yang sedang dilakukan. Fenomena ketika individu lebih memilih untuk berinteraksi dengan smartphone yang mereka miliki ketimbang berinteraksi langsung secara fisik ini merupakan sebuah istilah baru yang disebut dengan phubbing.

Phubbing merupakan fenomena yang rupanya sudah terjadi dalam skala yang besar di kehidupan kita. Namun pada realitanya, tidak semua orang mampu menyadari akan bahaya yang mengintai dari fenomena ini. Istilah phubbing merupakan sebuah singkatan dari kata phone dan snubbing, yang digunakan untuk menunjukan sikap menyakiti lawan bicara dengan menggunakan smartphone yang berlebihan (Hanika: 2015). Phubbing mampu menyebabkan penurunan relasi sosial antara pelaku dan penerima phubbing karena pengabaian atau pengucilan yang dilakukan baik secara sadar maupun tidak. Salah satu karakteristik phubbing yang juga dapat menurunkan relasi sosial ialah pengalihan kontak mata, dari yang seharusnya melihat ke lawan bicara namun teralihkan ke smartphone dan kemudian dapat ditafsirkan sebagai pemberian silent treatment, atau penolakan secara sosial.

Fenome phubbing tidak semata-mata langsung terjadi begitu saja. Perilaku yang secara berkesinambungan menggunakan smartphone secara tidak sadar membentuk perilaku yang mengarah ke phubbing. Seperti halnya hasil penelitian yang menunjukkan dimana penggunaan smartphone berlebih mempunyai korelasi positif terhadap perilaku phubbing (Chotpitayasunondh and Douglas, 2016). Penggunaan media sosial juga merupakan salah satu faktor penentu phubbing pada seseorang (Karadağ et al., 2015). Jika dahulu pepatah mengatakan jauh di mata dekat di hati, maka yang terjadi pada para perilaku phubbing justru sebaliknya. Ketika individu asyik menggunakan smartphone saat terlibat perbincangan, seringkali ia tak mengindahkan keberadaan lawan bicaranya. Sehingga hal yang dekat dimata menjadi jauh. Ironisnya, phubbing justru seringkali terjadi ketika momen kebersamaan sedang berlangsung. Alih-alih menjalin silaturahim, momen ketika berkumpul justru menjadi ajang saling menunduk dan senam jari.

Phubbing jika dilakukan sekali dua kali masih bisa dimaklumi bagi teman atau orang yang lebih tua dari kita, tapi jika dilakukan secara terus menerus berdampak merusak kualitas hubungan antar individu maupun kelompok (Alamudi; 2019). Ketika seorang individu merasa banyak orang yang melakukan phubbing, maka ia akan berpikir bahwa itu adalah hal wajar yang dapat diterima. Seperti yang dijelaskan dalam learning through modeling bahwa setiap individu melakukan observasi berupa modeling atau imitasi dan kemdudian mempresentasikan tingkah laku individu yang diobservasi secara kognitif. Ketika individu yang diobservasi menggunakan smartphone nya setiap waktu, maka akan menjadi panutan yang diikuti bentuk imitasi perilaku modeling, dimana individu yang mengamati adanya perilaku phubbing itu akan mengaggap phubbing sebagai hal biasa dan malah melakukan hal yang sama tanpa berpikir untuk mengatasi situasi yang terjadi. Phubbing menunjukkan betapa setiap individu saat ini telah menjadi manusia yang asyik sendiri dengan smartphone yang dimiliki, terutama dalam hal menggunakan sosial media, sampai akhirnya tidak terlalu memperdulikan orang di sekitarnya sehingga menyebabkan terjadi degradasi relasi sosial yang semakin hari menjadi semakin parah. Karenanya diperlukan pembentukan kesadaran bagi setiap individu dalam memahami fenomena phubbing.

\section{METODE}

Artikel ini akan menjabarkan tentang fenomena phubbing yang merupakan suatu degradasi relasi sosial sebagai dampak dari media sosial. Pendekatan kualitatif dengan metode deskriptif digunakan sebagai acuan penulisan artikel, dikarenakan data yang diteliti berupa gambar serta kata-kata dan bukan angka-angka dalam sebuah wacana mengenai fenomena 
phubbing: suatu degradasi relasi sosial sebagai dampak dari media sosial. Data yang digunakan pada penelitian ini merupakan data yang bersifat kualitatif sebagai data primer. Kemudian hasil analisis disaring intisarinya untuk kemudian dilanjutkan pada proses reduksi pengkajian data referensi dan dikorelasikan lagi dengan gagasan dan konsep referensi yang digunakan. Penelitian ini bukan bermaksud untuk mendapatkan external validity, melainkan lebih bertujuan untuk memperoleh pemahaman realitas di dalam konteksnya yang spesifik.

\section{HASIL DAN BAHASAN \\ Fenomena Phubbing}

Phubbing berasal dari kata phone dan snubbing, yang artinya adalah telefon dan menghina yang secara istilah menggambarkan tindakan menghina seseorang dalam lingkungan sosial dengan memperhatikan gawai (smartphone), bukan berbicara dengan orang tersebut secara langsung (Haigh, 2012). Phubbing adalah kondisi dua orang atau lebih dalam suatu lingkungan, tetapi mereka berinteraksi lebih banyak dengan smartphone-nya dibandingkan dengan sesama mereka (Chotpitayasunondh dan Douglas, 2016). Istilah phubbing pada awalnya dikampanyekan oleh Macquarie Dictionary untuk mewakili masalah penyalahgunaan ponsel cerdas yang terus berkembang dalam situasi sosial. Dalam interaksi sosial, phubber dapat didefinisikan sebagai seseorang yang memulai Phubbing, dan phubbee dapat didefinisikan sebagai orang yang menerima perilaku Phubbing (Varoth, 2017).

Adapun indikator fenomena phubbing dari berbagai teori yang ada, penulis rumuskan sebagai berikut :

1. Perilaku phubbing merupakan perilaku kurang aktif dalam berkomunikasi ketika individu sedang berada di tengah-tengah kontak sosial primer yang sifatnya langsung/tatap muka. (Turnbull, 2010) mengemukakan bahwa seseorang yang banyak menghabiskan waktu untuk mengakses internet, maka dia hanya punya sedikit waktu untuk berkomunikasi dengan orang lain secara nyata.

2. Selalu memperhatikan smartphone dan sibuk bermain sosial media tanpa menghiraukan pembicaraan lawan bicaranya. Sehingga dapat menyebabkan degradasi relasi sosial antar individu yang melakukan dan menerima phubbing.

3. Pada awalnya perilaku phubbing dilakukan secara tidak sadar, namun lama kelamaan menjadi kebiasaan yang dianggap normal. Smartphone mulanya hanya digunakan untuk mencari kenyamanan, hiburan, dan informasi terkini. Namun lama kelamaan menjadi kebutuhan primer dan menimbulkan fear of missing out terhadap segala hal di media sosial.

Pelaku phubbing akan merasa bahwa ia telah menjalankan interaksi dengan orang lain meskipun melalui perantara smartphone. Bahkan ia mampu menjalin interaksi dengan orang yang berada jauh darinya, tetapi ia tidak sadar bahwa interaksinya dengan lingkungan sosial tempat ia berada menjadi terdegradasi karena ia lebih sibuk dengan dunia maya smartphone (Abdul; 2019). Tidak dapat dipungkiri bahwa untuk berbicara dengan orang lain tanpa bermain smartphone menjadi hal yang sulit oleh kebanyakan orang, bahkan orang-orang akan lebih memilih berdiam diri di kamar sembari memainkan smartphone-nya daripada menjalin hubungan dan relasi sosial di luaran sana. Mereka beranggapan bahwa dengan smartphone saja ia bisa menjangkau informasi berdasarkan update status dari orang-orang di media sosial, sehingga ia tidak perlu capek-capek ke luar rumah untuk mendapatkan informasi lagi.

Perilaku phubbing mampu mengancam terganggunya hubungan dalam keluarga, pertemanan, persahabatan dan juga perilaku phubbing yang mengabaikan dan tidak memedulikan orang lain ini akan mengancam ketidakpercayaan orang terhadapnya serta mengakibatkan degradasi relasi sosial yang cukup parah (David, 2017). Orang yang sering berperilaku phubbing seringkali mendapat teguran dari orang-orang yang berada di lingkungannya, sesaat ditegur memang ia akan menghentikan fokusnya dari smartphone tetapi selang beberapa saat ia kembali melakukan perilaku tersebut. Smartphone seolah menjadi candu yang tidak lagi dapat dipisahkan, bahkan untuk beberapa jam saja. Secara umum durasi pemakaian smartphone dalam sehari berkisar dari 5 jam sampai hampir 24 jam. Setiap individu dengan mudahnya mampu fokus menggunakan smartphone meski di tengah keramaian hingga 
melupakan hal lain yang bahkan sudah ada di hadapannya secara langsung.

Orang yang tergolong ke dalam pelaku phubbing sekalipun tidak akan menyukai jika orang-orang di sekitarnya mengabaikan dan tidak memperdulikannya (Pratiwi; 2020). Seharusnya jika seseorang ingin tidak di acuhkan dan dihargai, orang tersebut juga harus belajar untuk tidak mengacuhkan dan menghargai orang lain karena bisa jadi orang-orang yang tidak menghargai kita berperilaku demikian karena kita tidak menghargainnya pula.

\section{Media Sosial dan Dampaknya}

Media sosial (social media) disingkat medsos, terdiri dari dua kata yang berbeda, yaitu media (alat, sarana komunikasi, perantara, penghubung), dan sosial (berkenaan dengan masyarakat atau merujuk pada cara orang berinteraksi). Kaplan \& Haenlein merumuskan media sosial yaitu sebuah aplikasi berbasis internet yang memungkinkan terjadinya penciptaan dan pertukaran konten yang diciptakan oleh penggunanya (Fatmawati; 2017). Media sosial merupakan suatu bentuk internet yang berkembang pesat. Data dari Kementrian Komunikasi Dan Informatika (Kemenkominfo) tahun 2013 (kominfo.com), mengungkapkan bahwa jumlah pengguna internet di Indonesia saat ini mencapai 63 juta orang. Dari angka tersebut, 95 persennya menggunakan internet untuk mengakses jejaring sosial.

Media sosial merupakan bentuk nyata dari media baru (new media) berbasis TIK. Jika media konvensional masih menggunakan media cetak semata, lain halnya dengan media sosial. Media sosial mengajak siapapun yang tertarik untuk memberikan partisipasi dengan cara pemberian feedback terbuka, saling memberi komentar, serta menyebarkan informasi dalam waktu yang cepat dan tak terbatas. Media sosial merupakan kombinasi dari tiga elemen, yaitu content, komunitas, dan teknologi Web 2.0. Perkembangan dari media sosial akan berdampak pada tiga area, yaitu masyarakat, perusahaan, dan lingkungan lokal (Ahlqvist et. al; 2012). Teknologi media sosial menggabungkan model-model seperti majalah, forum internet, weblogs, sosial blog, microblogging, wikis, jaringan sosial, gambar, video, dan lain-lain. Menurut Nasrullah (2016) Media sosial mempunyai karakteristik yaitu:

1. Jaringan (network) Antar Pengguna, Media sosial dapat terbangun dari struktur sosial yang terbentuk di dalam jaringan atau internet.

2. Informasi (Information), Informasi menjadi entitas yang penting dari media sosial. Tak seperti media lainnya di internet, pengguna media sosial mengkreasikan merepresentasi identitasnya, melakukan interaksi berdasarkan informasi, menjadi komoditas yang dikonsumsi antar pengguna.

3. Interaksi, Secara sederhana interkasi yang terjadi di media sosial minimal berbentuk saling mengomentari atau memberikan tanda seperti jempol "like".

4. Penyebaran (Share/sharing), adalah komentar yang tidak sekedar opini, tetapi juga data atau fakta terbaru. Penyebaran menjadi penting dimedia sosial diantaranya upaya membagi informasi yang dianggap penting kepada komunitas media sosial lainnya, menunjukan posisi terhadap sebuah isu atau informasi yang disebarkan, konten yang disebarkan merupakan sarana untuk menambah informasi atau data baru lainnya sehingga konten menjadi semakin lengkap.

Media sosial memiliki beberapa dampak positif diantaranya begitu mudah digunakan (user friendly), memiliki jangkauan global, siapapun dapat berbagi informasi lebih cepat secara real time, maupun dapat mengukur efektivitas informasi yang dibagi melalui respon yang muncul. Media sosial juga telah menghapus batasan-batasan dalam bersosialisasi. Dalam media sosial tidak ada batasan ruang dan waktu lagi, semua dapat diakses dengan mudah kapan saja dan dimana saja. Namun tidak dipungkiri pula media sosial memiliki dampak yang membahayakan, diantaranya semakin berkurangnya interaksi sosial di dunia nyata. Individu tidak perlu lagi saling bertemu langsung untuk berkomunikasi sehingga pola hidup sosial yang terjadi di masyarakat akan menjadi semakin tertutup.

Pada awalnya situs-situs jejaring sosial isinya lebih banyak terkait hal-hal yang sifatnya fun dan nostalgia ria tapi selanjutnya terjadi perkembangan yang mengarah ke arah profesionalisme. Dari sekedar komunitas biasa/pertemanan, lalu bertransformasi menjadi 
tempat untuk melakukan kontak yang lebih intens (Aljawiy dan Muklason; 2011). Hal yang ada di media sosial seakan lebih menarik untuk diketahui dari pada hal yang ada di dekat kita. Fokus dan perhatian yang biasanya tertuju pada lawan berinteraksi, langsung berubah menjadi terfokuskan ke media sosial yang ada di smartphone sehingga terjadilah fenomen phubbing yang kemudian berpengaruh pada degradasi relasi sosial.

\section{Phubbing dan Degradasi Relasi Sosial Sebagai Dampak Media Sosial}

Maraknya penggunaan media sosial melalui media baru berupa smartphone menghadirkan keberagaman fenomena sosial baru, diantaranya yaitu phubbing sebagai bentuk degradasi relasi sosial yang nyata terjadi. Phubber sebagai pelau Phubbing menggunakan smartphone sebagai pelarian untuk menghindari ketidaknyamanan di keramaian atau lazim disebut awkward silent (merasa canggung untuk berdiam diri), seperti, di dalam lift, bepergian sendiri dengan naik bus, bosan di pesta atau bahkan pada saat berkerumun dengan temantemanya dalam suatu tempat, namun ia lebih nyaman untuk ber-smartphone ria.

Tingkat penggunaan media sosial yang tinggi akan berpengaruh terhadap relasi sosial. Relasi sosial merupakan hubungan sosial yang dihasilkan dari interaksi diantara dua orang atau lebih. Indah (2016) menyatakan bahwa hubungan sosial atau relasi sosial merupakan suatu hubungan yang terjadi secara timbal balik antar individu yang satu dengan individu yang lain, saling mempengaruhi dan didasarkan pada kesadaran untuk saling menolong. Ketika relasi sosial seorang individu terdegradasi maka akan menimbulkan kekurangmampuan dalam menjalankan kehidupan sosial secara normal. Individu tersebut akan menjadi seperti malu, menarik diri, mengalami kecemasan sosial serta merasa kesepian. Hal ini akan menjadikan individu lebih memilih media sosial sebagai pengalihan dari interaksinya di kehidupan nyata sehingga terjadilah fenomen phubbing.

Istilah phubbing merupakan sebuah singkatan dari kata phone dan snubbing, yang digunakan untuk menunjukan sikap menyakiti lawan bicara dengan menggunakan smartphone yang berlebihan. Degradasi relasi sosial berupa phubbing sebagai dampak media sosial dapat menurunkan lima aspek kualias komunikasi, yaitu:

1. Keterbukaan, adalah untuk menyampaikan dan mengungkapkan segala sesuatu yang ada pada diri individu

2. Empati, adalah dapat merasakan seperti yang dirasakan oleh orang lain secara intelektual maupun emosional

3. Kesetaraan, adalah untuk menyeimbangkan kedudukan dan tanggung jawab antar individu

4. Kepercayaan, adalah untuk menghilangkan prasangka dan kecurigaan antara individu

5. Sikap mendukung, adalah untuk memberikan dukungan secara terucap maupun tidak terucap

Ketika lima aspek ini menurun, maka relasi sosial individu tersebut dapat dipastikan menurun pula. Ketika hal ini terjadi, maka individu bisa saja memperolah pengucilan sosial atas tindakan yang ia lakukan. Tumbuhnya relasi sosial dapat diawali dengan interaksi antar individu yang saling menegur, bejabat tangan, dan saling berkomunikasi. Dapat dipahami bahwa relasi sosial terjadi karena adanya individu yang saling membutuhkan antar individu dengan individu lainnya, relasi sosial ini dimulai dari tingkat yang sederhana dan tidak terbatas sampai tingkat yang lebih luas dan kompleks. Idealnya semakin dewasa dan bertambah umur tingkat relasi sosial makin berkembang dan menjadi amat luas dan kompleks. Namun apabila seorang individu tidak mampu mengendalikan dirinya dalam penggunaan media sosial dan smartphone tentu saja akan berdampak pada terdegrasasinya relasi sosial yang dimiliki.

Phubbing tetap memiliki hal positif jika dikaji lebih lanjut. Ketika seseorang mendapatkan perilaku phubbing dari lawan bicaranya tentu akan terjadi dua kemungkinan. Yang pertama ialah ia akan ikut melakukan phubbing atau kebalikannya ia menjadi mengertii seberapa bahaya phubbing. Sehingga individu yang memiliki kesadaran akan fenomena ini akan berusaha lebih aktif berinteraksi dan membangun relasi sosial di dunia nyata, individu ini akan berorientasi pada tujuan tertentu dan tidak menganggap bahwa media sosial adalah 
satu-satunya cara untuk berinteraksi dengan orang lain. Mereka tidak mudah terpengaruh apa yang diberikan oleh media kepadanya. Individu membentuk pemahaman sendiri akan isi dan makna media dan mereka secara aktif memutuskan bagaimana menggunakan media (Niekamp, 2003). Kesadaran dalam diri individu terkait fenomen phubbing malah akan membuat relasi sosial semakin intens akibat munculnya kecemasan akan terjadinya degredasi relasi sosil yang dijalani.

\section{SIMPULAN}

Fenome phubbing tidak semata-mata langsung terjadi begitu saja. Perilaku yang terjadi secara berkesinambungan menggunakan smartphone secara tidak sadar membentuk perilaku yang mengarah ke phubbing. Istilah phubbing merupakan sebuah singkatan dari kata phone dan snubbing, yang digunakan untuk menunjukan sikap menyakiti lawan bicara dengan menggunakan smartphone yang berlebihan. Ironisnya, phubbing justru seringkali terjadi ketika momen kebersamaan sedang berlangsung. Alih-alih menjalin silaturahim, momen ketika berkumpul justru menjadi ajang saling menunduk dan senam jari. Smartphone yang berada dalam genggaman dirasa lebih efektif untuk membangun interaksi dan relasi di dunia luar.

Smartphone seolah menjadi candu yang lebih mengasyikkan dibandingkan dengan hal yang terjadi langsung di hadapan kita. Ironisnya bahkan ketika berkomunikasi secara langsung dengan tatap muka, individu masih lebih banyak mementingkan apa yang harus ditampilkan di media sosial ketimbang bagaimana membangun interaksi dan relasi yang baik. Sehingga intensitas kedekatan malah menjadi berkurang meskipun telah bertemu, berbanding terbalik dengan intensitas ketika bertemu melalui media sosial yang ada di smartphone. Secara umum durasi pemakaian smartphone dalam sehari berkisar dari 5 jam sampai hampir 24 jam. Lingkup durasi yang lama ini menjadikan setiap individu semakin acuh terhadap relasi sosial nya masing-masing. Ketika phubbing terjadi pada diri individu, kecenderungan untuk merespon balik dengan memberikan perilaku phubbing pula seakan lebih mudah dilakukan ketimbang berusaha memperbaiki relasi dengan mengefektifkan komunikasi langsung yang sedang terjadi sehingga degradasi sosial tidak lagi dapat dihindari. Degradasi sosial yang terjadi disebabkan oleh dampak dari keacuhan pelaku phubbing terhadap lingkungannya karena terlalu sibuk menggunakan smartphone, terlebih dalam penggunaan media sosial. Karenanya diperlukan pembatasan dan pengendalian penggunaan media sosial yang baik agar fenomena phubbing dapat segera teratasi dan degradasi relasi sosial tidak terjadi.

\section{PUSTAKA ACUAN}

Ahlqvist, T., Back, A., Halonen, M., Heinonen, S. (2012). Social Media Roadmaps

Azizi, Abdul. No Mobile Phone Phobia di Kalangan Mahasiswa Pascasarjana. (2019)Jurnal Bimbingan dan Konseling. Vol 6 No 1

Alamudi, Farida Syafira Nadjib Ahmad. (2019). Sosial Phubbing di Kalangan Mahasiswa Fakultas Psikologi Universitas Negeri Makassar. Jurnal Sosialisasi. Vol. 6 Edisi 3

Aljawiy, Abdillah Yafi, dan Ahmad Ahmad Muklason. (2011). Jejaring Sosial dan Dampak Bagi Penggunanya. Jurnal IImiah Sistem Informasi. Vol, 1 No 1

Barker, Chris. 2008. Cultural Studies Teori Dan Praktik. Bantul: Kreasi Wacana

Chotpitayasunondh, V. and Douglas, K. M. (2016). How "phubbing" becomes the norm: The antecedents and consequences of snubbing via smartphone", Computers in Human Behavior. Elsevier Ltd, 63, pp. 9-18. doi: 10.1016/j.chb.2016.05.018.

C.K, Varoth. (2017). The effects of "phubbing" on social interaction. Journal Of Applied Social Psychology, Vol 1 No 33

Fatmawati, Endang. (2017)Dampak Media Soisal Terhadap Perpustakaan. Jurnal Libraria. Vol. 5 No.1

Fitria, Rini dan Rafinita Aditia (2019). Prospek dan Tantangan Dakwah Bil Qalam sebagai Metode Komunikasi Dakwah. Jurnal Ilmiah Syi'ar: Vol. 19 No. 2

Haigh, N. (2012). Diambil kembali dari www.stopphubbing.com

Hanika, Ita Musfirowati (2015). Fenomen Phubbing di Era Milenial (Ketergantungan Seseorang 
pada Smartphone terhadap Lingkungannya). Jurnal Interaksi. Vol. 4 No.1

Indah, Arina. (2016). Relasi Sosial Mahasiswa yang Menggunakan Smartphone (studi kasus: Mahasiswa/i Ilmu Kesejahteraan Sosial Universitas Sumatera Utara). Skripsi. Medan: Universitas Sumatera Utara

J Turnbull. (2010). Oxford Advanced Learner's Dictionary. New York: Oxford Exploring the futures triggered by social media. VTT Tiedotteita - Valtion Teknillinen Tutkimuskeskus.

Karadağ, E. et al (2015). Determinants of phubbing, which is the sum of many virtual addictions: A structural equation model. Journal of Behavioral Addictions. Akademiai Kiado Rt., 4(2), pp. 60-74. doi: 10.1556/2006.4.2015.005.

Niekamp, Raymond A. (2003). Audience Activity Among Users Of The World Wide Web. A Thesis, The Pennsylvania State University.

Pratiwi, Zolla Surya (2020). Phubbing Sebagai Sebuah Fenomena Budaya Pop Studi Kasus Pada Mahasiswa Fakultas Ilmu Sosial dan Politik universitas Andalas. Jurnal Kesejahteraan dan Pelayanan Sosial. Vol. 1 No.1

Turkle, Sherry. (2011). Alone Together: Why We Expect More From Technology and Less From Each Other. New York: Basic Books 